\title{
The Morphosyntax of Portuguese and Spanish in Latin America
}

\author{
Ed. by M.A. Kato and F.Ordóñez
}

Oxford Studies in Comparative Syntax: Oxford University Press, 366 pages.

ISBN: 9780190465896

Received: 08-07-17

Accepted: 27-12-17

\author{
Reviewed by Rosa Bono Velilla \\ Universitat Autònoma de Barcelona
}

The volume here reviewed comes about as the result of a project called Romania Nova, launched by the Associação de Linguística e Filologia da America Latina (ALFAL) in 2005 in Mexico. The broad aim of this undertaking was to study and bring into comparison the properties of Romance languages in Europe and Latin America, as well as to explain how Romance varieties differ from each other in this last geographical area. Even though a fair variety of languages is indeed discussed by the authors who have joined their work together in this book, it is worth noting at this point that it will turn out particularly useful for those readers wrapped up in Brazilian Portugese (on which nearly all articles comment and many focus). Only chapter ten deals exclusively with varieties of Spanish. Nonetheless, the total number of languages comprised by this work -either for exhaustive investigation or by mere allusion- add up to thirty-three, including Japanese, Bulgarian, Hebrew and West African.

Chomsky's Principles and Parameters theory (Lectures on Government and Binding, 1981) serves as the essential framework for the fourteen papers assembled by Mary A. Kato and Francisco Ordoñez in the book. Inscribed in such understanding of human language as a set of principles subject to a range of different realisations, this work abides by a microparametric approach, as proposed by Keyne (Parameters and Universals, 2000), who fosters the study of language architecture based on comparison among similar languages or even different varieties of the same language. Along these lines, the analysis of the morphosyntactic properties of Latin-American Portuguese and Spanish eventually contributes to a more general scope of linguistic variation and the faculty of language. Thus, for instance -as the editors well point out-, comparing how null subjects operate in Brazilian and European Portuguese has been decisive for a satisfactory formulation of the Null Subject Parameter.

In accord with the standpoint above, the editors strive to clarify how the binary division proposed by the title and the subsequent labels for the variants only intend to provide a handy way to bind the many realisations of these languages together, instead of suggesting the isolated uniformity of such rich systems. The division of Spanish and Portuguese itself is in fact considered "a continuum of varieties" (viii). 
The careful order in which the chapters are structured also forms a succession of bound topics covering several basic concepts and how these varieties conform to them. Thirteen out of fourteen articles stick to the study of syntax, gathering multiple aspects in the following main points:

$\begin{array}{ll}\text { 1. } & \text { Subjects } \\ \text { 2. } & \text { Infinitives } \\ \text { 3. } & \text { Objects } \\ \text { 4. } & \text { Wh-constructions }\end{array}$

An overview of the structure and contents of the book will certainly be useful for those readers interested in the matter. A 'Foreword' by the editors precedes the block of chapters, which are carefully subdivided into several sections that expedite their reading, eventually drawing clear and complete conclusions and noting down some comments by the authors. Each article gathers all the bibliographical sources employed at the end of it, providing extra materials that allow for a deepening (in a particular topic) and widening (towards more general matters) of the covered domain. The volume is closed by a set of indexes on the concepts, authors and languages cited along its pages.

Regarding content, the first six articles focus on the domain of subjects. Maria Duarte and Humberto Soares consider the role of the inflectional paradigms in the distribution of null subjects in Italian and some varieties of Latin American Spanish and Portuguese, arguing how simpler paradigms show a tendency for overt subjects or referential pronominal subjects. Other factors are taken into account, such as the semantic properties of the element (animacity) and the influence of the structural pattern (c-commanding relations).

Turning to the Minimalist Program (Chomsky 1993) as a basis for his proposals, José Camacho contributes to the topic with his research on referentiality of null subjects and their relation to inflection, which is conditioned by locality constraints for grammatical operations such as AGREE.

Andrés Saab takes up the torch and addresses the notion of partial prodrop in Northern Italian dialects and Brazilian Portuguese. He argues that the empirical contrasts which arise in these languages suggest a particular way to study the Null Subject Parameter, in which the operation of ellipsis is crucial to explain how apparently similar partial pro-drop languages display different behaviours in this regard. The problem would be solved either at syntax or at Phonetic Form, depending on the language analysed. In chapter four, floating quantifiers in Brazilian Portuguese and Spanish constitute Renato Lacerda's central study focus, which he tackles by proposing cartographical differences in each language. Aspects like informative structure -focalization- and extraction possibilities take part in this syntactic process, but it is ultimately explained by the optional assignation of abstract Case to QP-type quantifiers.

Hyper-raising is discussed in the last two chapters of the first part by Jairo Nunes (Chapter 5) and Madalena Colaço and Anabela Gonçalves (Chapter 6). Nunes studies cases of Brazilian Portuguese that display two subject-like positions, in which topics may agree with the verb depending on processes such as resumption, matrix and embedded asymmetries, or wh-extraction. Thus, what seems to be carried through agreement and movement actually consists on 
derivation, according to minimalist proposals by which -as the author puts it"agreement and movement are still taken to be last-resort operations". On the other hand, Colaçao and Gonçalves slightly drift to the next topic by introducing the infinitive form in $\mathrm{V}$-and- $\mathrm{V}$ constructions, although still applying their study to subjects. They consider that hyper-raising is also found in $<$ ir-e-V $>$ structures in Portuguese -the embedded CP where the subject is merged lifts to receive Caseand elaborate a set of principles that make this structure differ from other kinds of verb clusters.

Already fully immerse in the second topic, Marcelo Modesto studies inflected infinitives in Brazilian Portuguese in chapter seven, particularly the contrast between two types of predicates corresponding Landau's partial control and exhaustive control classes. In this paper, the author relevantly proves how the studied language, despite lacking clitic climbing, shows cases of restructuring.

In the same way as the first part, the third block is opened by Sonia Cyrino dealing with null status, this time regarding objects in several Romance languages. The author compares Portuguese and Spanish but specially looks at Brazilian Portuguese, where the object undergoes a process of VP movement, which in turn makes ellipsis possible. Maria Torres and Heloisa Lima-Salles add to the topic by looking at structures in Portuguese where two nominals are semantically related by possession: the "possessor" behaves as an argument of the verb to which the related element is nevertheless syntactically external. Working with low applicatives (prepositions that govern these elements, such as 'to', 'from' and 'at') and movement, they manage to explain how these contrasts actually work. Chapter ten closes objects domain with an analysis of DOM in Mexican and Peninsular Spanish. Francisco Ordóñez and Esthela Treviño prove, for instance, how agreement between a DOM argument and the verb can take place considering that $\mathrm{vP}$ is not a phase and DOM can thus become a goal for Tense.

The next three chapters cover the last topic on syntax: wh-constructions. Maria Figueiredo and Elaine Grolla consider the pragmatic and syntactic constraints -such as a request for immediately previous information and focalization, respectively- that make WH elements move or stay in-situ (or even be subject to both processes) in Brazilian Portuguese. Pseudo-clefts and semi-clefts are the object of study for Mary Kato and Carlos Mioto in the following chapter. While the first type is commonly found in Romance, semi-clefts (where the wh-element is erased, as happens in Japanese) are quite unusual. The authors argue that these structures, although apparently similar, are independent; and also that in the second type, a process of narrow focalization occurs where the absence of an wh-element triggers focalization of a remnant VP of any kind (complements, predicates, adverbs). Chapter thirteen, by Paulo Medeiros, offers a diachronic analysis of Free Relatives in Portuguese containing [o que]. Classic Portuguese held two structures for this construction: one where $o$ would be the antecedent of que $-\left[{ }_{\mathrm{DP}} \mathrm{O}\left[{ }_{\mathrm{CP}} q u e\right]\right]-$ and another where $o$ que forms a single unit -[ ${ }_{\mathrm{DP}} \mathrm{O}$ que]-, which has gradually gained on the first one (as seems to have happened in Spanish).

Ana P. Scher closes the reviewed volume with a paper on morphology that complies with the theory of Distributed Morphology in its analysis of truncated nouns and adjectives such as 'bermas $<$ bermuda (shorts)' or 'padoca $<$ padaria (baker shop)' in Brazilian Portuguese. She argues however that the process 
undergone by these words is not one of shortening but of derivation from a root or stem instead.

As we can already infer, reading this book will provide a solid empirical and theoretical ground for those drawn by the configuration of Romance languages; the core topics and concepts that determine their architecture are thoroughly analysed by it. Dialects are here studied by contrast, a perspective that abides by the notion of parameters that shape the diverse outcome of all languages; a diversity, however, that has been proved to carry an underlying shared structure, with systematic principles that ultimately account for it. These principles are our authors' target in two ways: they are an aim insofar as they serve to define the examined languages and to find general principles that can also apply to the rest of them, but they -those already formulated- form a set of tools for their inquiry at the same time. To accomplish this purpose, the twenty contributors of this volume base their work in the most updated syntactic and morphological theories, like Chomsky's Minimalist Program.

In accordance with the ever-forward-looking mindset entailed by such task, further research is steadily encouraged by the authors of the articles. Thus, these kinds of endeavours do not only considerably enhance our understanding of particular languages or families of languages, but eventually contribute to the development of generative grammar, taking part in the broad knowledge of how language as a human faculty works. Well versed readers, students and researchers will certainly make the most of the rich variety of topics assembled here, although amateur interest will also be satisfied and even boosted by the compelling approach put forward by this book. 